\title{
Technology innovation and sustainability: challenges and research needs
}

\author{
Yinlun Huang ${ }^{1}$
}

Published online: 12 July 2021

(c) The Author(s), under exclusive licence to Springer-Verlag GmbH Germany, part of Springer Nature 2021

Global environmental problems, such as depletion of natural resources, various types of environmental pollution and health risks, climate change, and loss of biodiversity, have become increasingly evident. Societies are more aware of the challenges than ever, and understand more deeply that pursuing sustainability is essential to environmental protection, economic growth, and social stability. Among solution approaches, technology innovation is a key, as it can influence prosperity, consumption pattern, lifestyle, social relation and cultural development. Technology determines, to a great extent, the demand for raw materials and energy, the ways and efficiency of manufacturing, product performance, waste reduction and waste handling, health and safety, transportation and infrastructure, etc., thereby making significant impacts on the economic, environmental, and social dimensions of industrial development. It is more widely recognized that sustainability is a key driver of innovation, and only those companies that make sustainability as a goal will achieve competitive advantage (Nidumolu et al. 2009; Kiron et al. 2012).

In the U.S., a new wave of technology innovations has arisen, largely due to the national endeavor to advance manufacturing in the thrust areas of national importance. The accelerated innovations entail rapid transfer of new technologies into design and manufacturing of high performance products and services. Although new and emerging technologies have become an engine of change and progress, the net improvement brought to the environment and society could be questionable, if sustainability principles are not fully incorporated into the technology development and application phases. For instance, although introduction of

Yinlun Huang-Associate editor.

Yinlun Huang

yhuang@wayne.edu

1 Department of Chemical Engineering and Materials Science, Wayne State University, Detroit, MI 48098, USA nanomaterials has created new opportunities for high performance applications and novel product introduction, there exist various concerns about negative impacts on health and the environment. Biofuel, as another example, can be converted directly from renewable sources, but its global emergence has led to the debate over the environmental impact, including global warming, due to growing vegetation used for biofuel manufacturing. All these demand thorough examination of economic, environmental and social aspects. Industries are more seriously conducting comprehensive sustainability assessment, and demand more sustainable technologies (Dornfeld 2014).

The essential component of industrial sustainability is three-pillar-based balanced development. This requires that technology innovations be shaped to incorporate sustainability principles fully throughout their development and application phases. It is imperative, therefore, to conduct a fundamental study on the sustainability dimensions of technology innovation, and develop systematic methodologies and effective tools for technology inventors, decision makers, and organizations to evaluate and maximize potential sustainability benefits of new and emerging technologies. In this endeavor, sustainability assessment of technology innovation, especially in its early development stage, is critical.

Technology assessment (TA) emerged in the 1970s as a research based policy advising activity. It constitutes a scientific and societal response to problems at the interface between technology and society. In the last decade or so, early engagement in TA occurred mainly in new and emerging products using, for example, nanotechnology and biotechnology (Grunwald 2009). Today, TA is considered a designation of approaches and methods for investigating the condition for and consequence of technologies, and for denoting their social evaluation. It is an interactive and communicative process that aims to contribute to the formation of public and political opinion on societal aspects of science and technology. A number of important concepts exist at the uppermost level of TA operationalization, such 
as participative technology assessment (evaluations participated by scientific experts, societal groups, and political decision makers), constructive technology assessment (constructive involvement of technology development process, aiming to analyze its enculturation by society), leitbild assessment (explanation of the course of technology development ex post rather than by giving indications on how to shape technology), and innovation-orientated technology assessment (analysis of completed and current innovation processes with primary interest in factors that are crucial to successful market penetration). The known methods for conducting TA are basically all derived based on participants' views, discussions, and group consensus, and applicable to the TA of individual technology rather than a group of them as a whole. However, there is a lack of scientific framework for systematic, integrated assessment of technology innovation in different life cycle stages. More critically, there has been no systematic methods for TA in the triple-bottomline-based sustainability space; this could lead to the whole spectrum of sustainability performance of technology innovations unclear.

Sustainability assessment (SA) is a very complex appraisal method. It entails not only multidimensional aspects that may be intertwined, but also cultural and valuebased elements. There exist numerous types of sustainability indicators for a variety of systems and applications in different fields, and methods for indicator formulation, scaling, normalization, weighting, and aggregation (Singh et al. 2012). Studies on assessment information aggregation leads to a creation of composite sustainability performance indices. Sikdar et al. (2012) stated that it is deemed desirable to consolidate all the usable indicators into one aggregate metric to make performance comparison easier. A main challenge in SA of technology innovation is how to conduct multiple life-cycle-stage based assessment and to compare sustainability performance under different scenarios, especially when the available system information is uncertain, incomplete and imprecise. In almost every phase of sustainability study, data and information uncertainty issues exist. Examples include the data about material or energy utilization, toxic/hazardous waste generation, and market fluctuation, the multifaceted makeup of the inter-entity dynamics, dependencies, and relationships, the prospect of forthcoming environmental policies, and the interrelationship among the triple-bottom-line aspects of sustainability, weighting methods, weights' values and aggregation methods. In technology innovation, uncertainty could be more severe, as many types of data and information are frequently unavailable and uncertain, and the relevant information from the literature or other sources may not be easily justifiable.

Apparently, an urgent research need is to develop sciencedriven frameworks for conducting systematic sustainability assessment of emerging technologies in their early development stage and recommending technologies sets after performing multistage sustainability impact evaluation (Huang 2020). Such frameworks should be composed of coherent sets of new concepts, propositions, assumptions, principles, and methodologies, as well as tools that could assist researchers, decision makers, and organizations in shaping technology innovations for industrial sustainability. This is certainly a very challenging task, especially when the world experiences major disruptions, such as COVID-19. However, the motivations for achieving industrial sustainable development goals should lead to the development of a new wave of highly sustainable technology innovations in the years to come.

Acknowledgements This work is supported in part by U.S. National Science Foundation (Award No. 2031385 and 1604756).

\section{References}

Dornfeld DA (2014) Moving towards green and sustainable manufacturing. Int J Precis Eng Manuf Green Technol 1(1):63-66

Grunwald A (2009) Technology assessment: concepts and methods. In: Meijers A (ed) Handbook of the philosophy of science, vol 9: philosophy of technology and engineering sciences. Elsevier

Huang Y (2020) Reinforcing sustainability assessment and reshaping technology innovation for highly sustainable manufacturing in the post-COVID-19 era. Smart Sustain Manuf Syst 4(3):341-345

Kiron D, Kruschwitz N, Reeves M, Goh E (2012) The benefits of sustainability-driven innovation. MIT Sloan Manag Rev 54:69

Nidumolu R, Prahalad CK, Rangaswami MR (2009) Why sustainability is now the key driver of innovation. Harvard Bus Rev 87:56-64

Sikdar SK, Sengupta D, Harten P (2012) More on aggregating multiple indicators into a single index for sustainability analyses. Clean Technol Environ Policy 14(5):765-773

Singh RK, Murty HR, Gupta SK, Dikshit AK (2012) An overview of sustainability assessment methodologies. Ecol Ind 15(1):281-299

Publisher's Note Springer Nature remains neutral with regard to jurisdictional claims in published maps and institutional affiliations. 